\title{
Impact of Upper Limb Joint Fluid Variation on Inflammatory Diseases Diagnosis
}

\author{
Hari Krishnan $\mathbf{G}^{\dagger}$, Ananda Natarajan $\mathbf{R}^{*}$ and Anima Nanda**
}

\begin{abstract}
Joint pain is generally a common disorder not only for the old aged people but also for the immunocompromised patients. The present proposed study reveals the presence of inflammatory diseases in joint generally diagnosed by removing synovial fluid and changes in the volume and composition are examined for the presence of WBC and crystals. This study implement a non-invasive approach to identify the changes in joint fluid by measuring the changes in electrical property of the synovial tissue under the influence of electrical current signal with frequency range between $100 \mathrm{kHz}$ to $300 \mathrm{kHz}$. The response of tissue for the current signal was measured in terms of potential drop across the tissue. The hardware system design consists of input and output sections. The input section which applies current signal to upper limb joint region is made of ICL8038 function generator IC with amplifier and voltage to current converter. The output section picks voltage variation using metal surface electrode, amplifier, ADC, PIC microcontroller and LCD interface. 100 patient inclusive of normal and disease affected patients where examined for upper limb synovial fluid variation and inflammatory diseases were identified.
\end{abstract}

Keywords: Non-invasive, Synovial fluid, Inflammatory disease, Function generator, PIC microcontroller

\section{Introduction}

The Synovial fluid is viscous and whose viscosity changes as a function of shear stress and time, which is normally found in joints, tendon sheaths, and fluid-filled sacs in the joints $[7,8]$. The synovial fluid contains 3 layers of synoviocytes which is loonnective tissue of fat, collagen and blood vessels and grows as layers that surround fluid filled spaces. During joint disease affected condition the synovium and surrounding muscles, ligaments and tendons weaken [5]. In Rheumatoid arthritis (RA) with and without joint effusion, Spondyloarthropathy $(\mathrm{SpA})$ with and without joint effusion and Osteoarthritis (OA) with and without joint effusion there is a variation in Mean lining thickness, Max lining thickness, Vascularity etc., of the synovial lining.

The Psoriatic arthritis, ankylosing spondylitis and undifferentiated spondyloarthropathy are few other interrelated groups of chronic inflammatory diseases [3, 4]. The internal surface of the synovial membrane is smooth, moist, glistening, and pink. Synovial tissue has shown an arrangement of internal surface cells, subintimal cell, connective tissue fibers, ground substance, nerves, blood vessels and lymphatics [6]. Resistance to joint motion comes from the stretching of surrounding soft tissue and

$\uparrow \quad$ Corresponding Author: Dept. of Biomedical Engineering, Sathyabama University, India. (haris eee@yahoo.com)

* Department of Electronics and Instrumentation Pondicherry Engineering College, India. (ananda_natarajan@pec.edu)

** Faculty of Bio and Chemical Engineering Sathyabama University, India.(biju_nandu@yahoo.com)

Received: September 14, 2013; Accepted: June 16, 2014 frictional resistance of the joint parts that must slide across each other. Synovial fluid level decrease is associated with joint diseases; Long tern patterns of variation have some prognostic value in human joint diseases patients [9].

The electrical property of synovial tissue can be obtained by measuring the developed voltage due to applied electrical signal. The synovial fluid level varies from normal patient to arthritis patient as disease prolongs due to weakening of synovium and surrounding muscle tissues. The synovial fluid density increases and WBC count increases across joint affected region. These weakening of muscle tissues can be observed in terms of variation in voltage drop due to applied high frequency electrical signal.

The system used to measure voltage drop is diverged in to two parts as input section and output section. The function of input section is providing high frequency current signal to synovial joint region. The function of output circuit is to pick the response in synovial joint region of the synovial tissue to electrical signal [10].

\section{Material \& Methods}

The passive electrical property of the synovial tissue to oppose the flow of current flowing through it gives rise to the prediction of presence of the joint diseases. There is a large difference in conductivity of each tissue between the liquid tissues flowing through the blood vessels to the myelin sheaths as insulator in axons of the nerve cells. The electrical property of the tissue can be altered by applying 


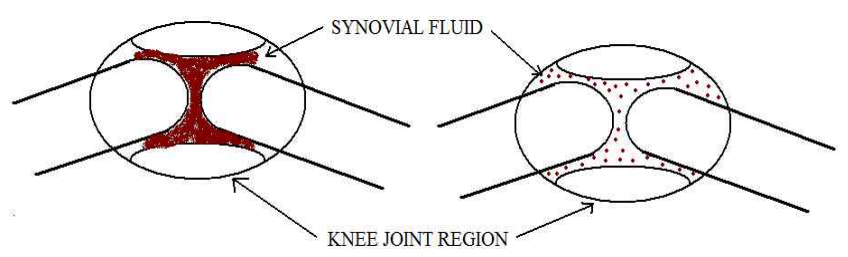

Fig. 1. Synovial fluid during normal and arthritis affected condition

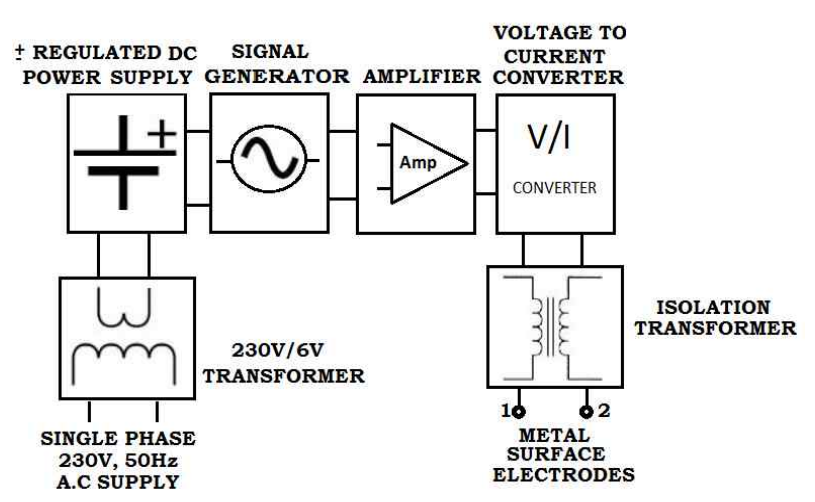

Fig. 2. Input section block diagram

signal with varying frequency.

The electrical bio impedance value of the normal joint region is less and conductivity is more. This weakening of muscle tissues can be observed in terms of variation in voltage drop due to applied high frequency electrical signal. Synovial fluid volume density is equally distributed in normal joint region but under joint disease affected condition synovial fluid volume density is non uniform. The fluid volume density is very high in joint region for joint disease (arthritis) affected patient.

The electrical bio impedance value of high fluid density region is more due to reduction in movement of charges leading to conductivity $[2,4]$. The electrical bio impedance value is measured in terms of voltage drop as resistance increases voltage drop increases according to Ohm's law. The normal and disease affected condition can be identified by measuring the voltage drop across the joint region. For normal patient joint region fluid density is less leading to more conductivity and similarly for arthritis affected patients joint region fluid density is large leading to less conductivity as shown in Fig. 1. If conductivity is more resistance or bio impedance is less leading to less voltage drop. If conductivity is less resistance is high leading to large voltage drop $[11,12]$.

The input section contains two metal surface electrodes 1 and 2 as shown in Fig. 2, voltage to current converter, Isolation transformer, Signal amplifier, high frequency signal generator and regulated power supply. Output section contains two metal surface electrodes 3 and 4 [1] as shown in Fig. 3, Analog to Digital converter, PIC Microcontroller, LCD interfacing and display.

The patient is isolated from high voltage $50 \mathrm{~Hz}$ frequency signal by providing two transformers in input

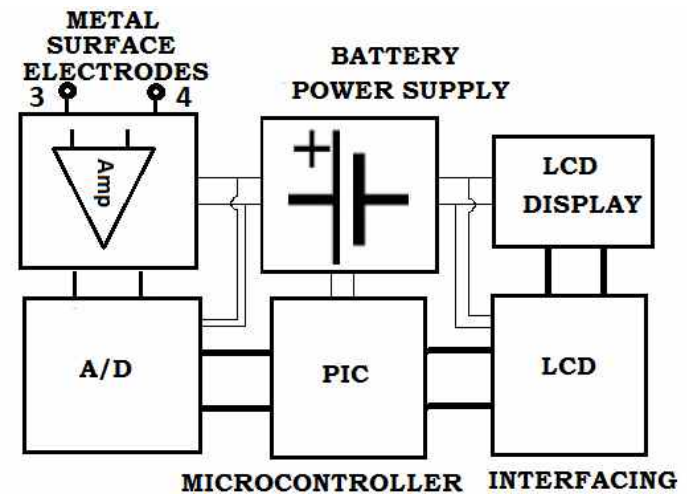

Fig. 3. Output section block diagram

section one $230 \mathrm{~V} / 6 \mathrm{~V}$ step down transformer and the other is $6 \mathrm{~V} / 6 \mathrm{~V}$ isolation transformer after amplification stage in the input circuit. In output section patient isolation is achieved by using $6 \mathrm{~V}$ long lasting battery for all devices in the output circuit.

\section{Results and Discussion}

The experiment has been conducted based on two categories, Normal male and female patients with different ages and arthritis affected male and female patients. During experimental analysis of first category we observed voltage drop across joint region ranges from $1.32 \mathrm{~V}$ to $2.45 \mathrm{~V}$ as shown in Table 1. Similarly under analysis of disease affected patient's voltage drop we observed voltage drops

Table 1. Type of patients and its corresponding grade value for different group patients

\begin{tabular}{c|c|c|c}
\hline Group & Type of patient & No. of patient & Grade value \\
\hline Group I & $\begin{array}{c}\text { Normal male patients age } \\
\text { group between 25 to 45 }\end{array}$ & 15 & $\begin{array}{c}1.32 \mathrm{~V}- \\
2.00 \mathrm{~V}\end{array}$ \\
\hline Group II & $\begin{array}{c}\text { Normal male patients age } \\
\text { group between 45 and above }\end{array}$ & 13 & $\begin{array}{c}2.00 \mathrm{~V}- \\
2.45 \mathrm{~V}\end{array}$ \\
\hline Group III & $\begin{array}{c}\text { Disease affected male } \\
\text { patients }\end{array}$ & 14 & $\begin{array}{c}2.78 \mathrm{~V}- \\
3.75 \mathrm{~V}\end{array}$ \\
\hline Group IV & $\begin{array}{c}\text { Normal female patients age } \\
\text { group between 25 to 45 }\end{array}$ & 19 & $\begin{array}{c}1.32 \mathrm{~V}- \\
2.00 \mathrm{~V}\end{array}$ \\
\hline Group V & $\begin{array}{c}\text { Normal female patients age } \\
\text { group between 45 and above }\end{array}$ & 23 & $\begin{array}{c}2.00 \mathrm{~V}- \\
2.45 \mathrm{~V}\end{array}$ \\
\hline Group VI & $\begin{array}{c}\text { Disease affected female } \\
\text { patients }\end{array}$ & 16 & $\begin{array}{c}2.78 \mathrm{~V}- \\
3.36 \mathrm{~V}\end{array}$ \\
\hline
\end{tabular}

OVERALL AGE VS GRADE PLOT (INCLUSIVE OF NORMAL/ABNORMAL \& MALE/FEMALE)

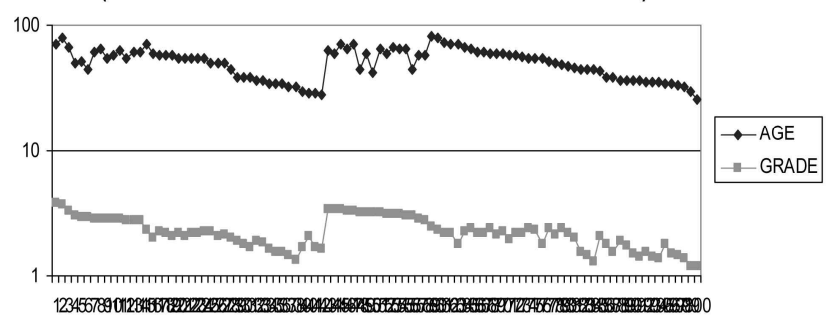

Fig. 4. Graph showing grade variation with respect to age 
ranges from $2.78 \mathrm{~V}$ to $3.75 \mathrm{~V}$ as shown in Table 1 . These experimental data confirms that young age patients have less voltage drop than old age patients for both normal male and female patients as shown in Figs. 5, 6, Figs. 8 and 9. Also voltage drop was high for advance stage arthritis patient than initial stage arthritis patient rather than age and gender as shown in Figs. 7 and 8. The overall voltage drop variation for normal and diseases affected male and female patients are as shown in Fig. 4.

To analyze the performance of the designed non invasive arthritis diagnosis system comparative study has been made with the conventional methods outcome. The 100 patients under the research are all diagnosed by conventional method and tested with non invasive system. The results of both methods were tabulated and analyzed. During these comparative analyze as shown in Table 2 we obtained

Table 2. Positive accuracy and error percentage value for different patient

\begin{tabular}{c|c|c|c|c}
\hline Group & Type of patient & $\begin{array}{c}\text { No. of } \\
\text { patients }\end{array}$ & $\begin{array}{c}\text { No. of } \\
\text { patient } \\
\text { diagnosed }\end{array}$ & $\begin{array}{c}+ \text { ve } \\
\text { accuracy } \\
\text { in \% }\end{array}$ \\
\hline Group I & $\begin{array}{c}\text { Normal male patients age } \\
\text { group between 25 to 45 }\end{array}$ & 15 & 14 & 93.33 \\
\hline Group II & $\begin{array}{c}\text { Normal male patients age } \\
\text { group between 45 and above }\end{array}$ & 13 & 12 & 92.3 \\
\hline Group III & Disease affected male patients & 14 & 13 & 92.86 \\
\hline \multicolumn{2}{|c|}{ Male patients } & 42 & 39 & 92.85 \\
\hline Group IV & $\begin{array}{c}\text { Normal female patients age } \\
\text { group between 25 to 45 }\end{array}$ & 19 & 18 & 94.70 \\
\hline Group V & $\begin{array}{c}\text { Normal female patients age } \\
\text { group between 45 and above }\end{array}$ & 23 & 21 & 91.30 \\
\hline Group VI & $\begin{array}{c}\text { Disease affected female } \\
\text { patients }\end{array}$ & 16 & 15 & 93.75 \\
\hline & Female Patients & 58 & 54 & 93.10 \\
\hline & Overall Patients & 100 & 93 & 93.00 \\
\hline
\end{tabular}

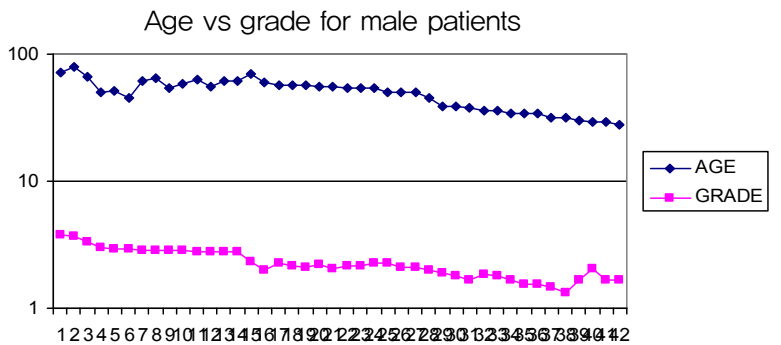

Fig. 5. Graph showing grade variation with respect to age for male patients

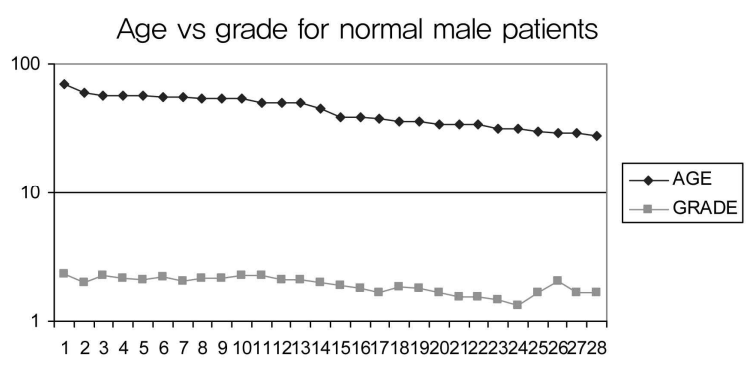

Fig. 6. Graph showing grade variation with respect to age for normal male patients approximately $93 \%$ of positive outcome. Based on the measured grade value for different group of patients the positive accuracy and error percentage value has been calculated by comparing with results obtained with conventional methods as shown in Table 2 .

The group 1 positive accuracy is around $93.33 \%$ and error is around $6.67 \%$ because out of 15 patients 14 were diagnosed correctly. Similarly for group 2 to group 6 the positive accuracy and error percentages are tabulated in Table 2. The normal and disease affected male patients positive accuracy is around $92.85 \%$ and for female the

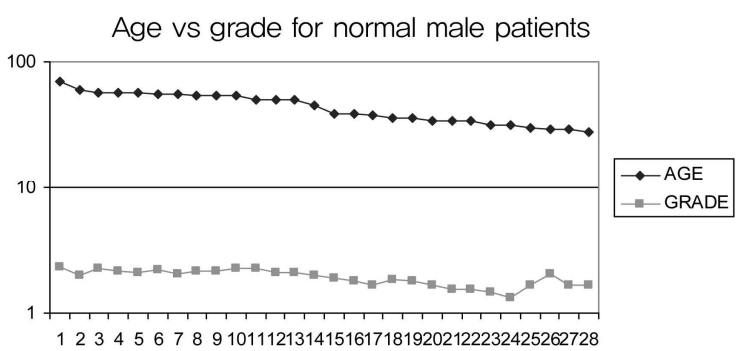

Fig. 7. Graph showing grade variation with respect to age for disease affected male patients

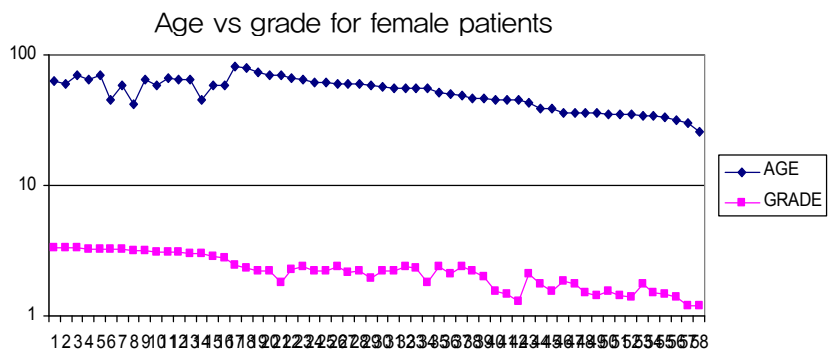

Fig. 8. Graph showing grade variation with respect to age for female patients

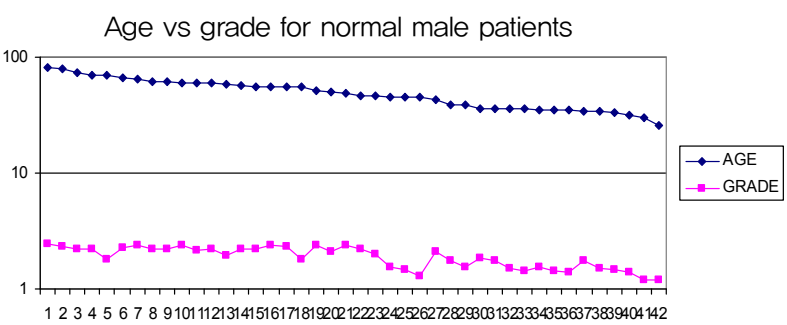

Fig. 9. Graph showing grade variation with respect to age for normal female patients

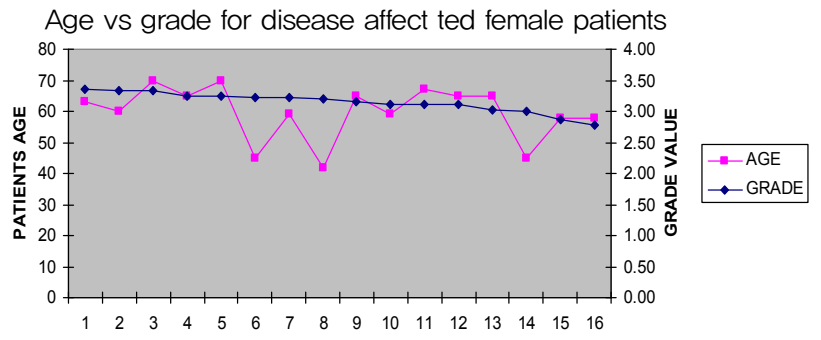

Fig. 10. Graph showing grade variation with respect to age for disease affected female patients 
positive accuracy is around $93.10 \%$. The overall positive accuracy inclusive of male and female is around 93\% and error percentage is around $7 \%$.

\section{Summary and Conclusion}

Based on observations made during current research on 100 normal and disease affected patients we conclude that voltage drop increases uniformly as age increases for normal patient category. For arthritis affected patients synovial fluid density increases based on disease condition rather than age and gender. This result indicates that synovial fluid density increases uniformly as age increases for normal patients and for arthritis patient synovial fluid volume change depends on arthritis disease level. Finally we confirm that designed non invasive system can be used for diagnosis of joint disease like arthritis.

\section{References}

[1] Aaron S. Tucker, Robert M and Rosalind J. Sadleir, "Biocompatible high precision, wideband improved howland current source with lead lag compensation". IEEE Transaction on Biomedical Circuits and systems, Year: 2013, Volume: 7, Issue: 1, Pages: 63-70.

[2] Damijan Miklavcic, Natasa Pavselj and Francis X. Hart, "Electrical properties of tissues", Wiley Encyclopedia of Biomedical Engineering, Copyright 2006 John Wiley \& Sons, Inc.

[3] D Baeten, P. Demetter, C Cuvelier, F van den Bosch, E Kruithof, N Van Damme, Ann Rheum Dis "Comparative study of the synovial histology in rheumatoid arthritis, spondyloarthropathy, and osteoarthritis; influence of disease duration and activity", 2000; 59: 945-953.

[4] F. Ibrahim, N. A. Ismail, M. N. Taib, W. A. B. Wan Abas, S. Sulaiman, and C. C. Guan, "Assessment of haematocrit status using bioelectrical impedance analysis in dengue patients", IFAC Modeling and Control in Biomedical Systems, Melbourne, Australia, 2003.

[5] Hari Krishnan G, Ananda Natarajan R, Anima Nanda. "Detection of synovial fluid variation and its impact on joint diseases diagnosis". Indian conference on Applied Mechanics, IIT Madras, year: 2013.

[6] K. S. Cheng, C. Y. Chen, M. W. Huang, and C. H. Chen, "A Multi-Frequency Current Source For Bioimpedance Application", 5th International IEEE EMBS Special Topic Conference on Information Technology in Biomedicine, 2006.

[7] Michael T. Cibulka, and Julie Threlkeld, "The Early Clinical Diagnosis of Osteoarthritis of the Hip", Journal of Orthopaedic \& Sports Physical Therapy, Volume 34, Number 8, August 2004.

[8] Paul H. Curtiss, JR., M.D., Cleveland, Ohio, "Changes produced in the Synovial membrane and synovial fluid by disease", The American Academy of Orthopaedic Surgeons, Vol., 46-A June 1964.

[9] PL Cox-Reijven and PB Soeters, "Validation of bioimpedance spectroscopy: Effects of degree of obesity and ways of calculating volumes from measured resistance values", International Journal of Obesity, Year 2000, Volume 24, Pages 271-280.

[10] Swan A, Amer H, Dieppe P, "The value of synovial fluid assays in the diagnosis of joint disease: a literature survey", Ann Rheum Dis 2002;61:493-8.

[11] Tercic D, Bozic B, "The basis of the synovial fluid analysis", Clin Chem Lab Med 2001;39:1221-6.

[12] S. Zlochiver, M. Arad, M.M. Radai, D. Barak-Shinar, H. Krief, T. Engelman, R. Ben-Yehuda, A. Adunsky, S. Abboud. "A portable bio-impedance system for monitoring lung resistivity". Medical Engineering \& Physics, Volume: 29, Year: 2007, Pages: 93-100.

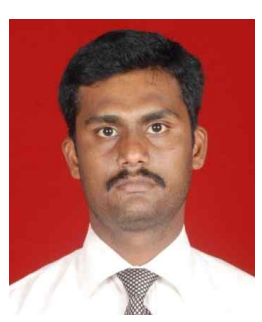

Hari Krishnan G He received B.E degree in Electrical and Electronics Engineering and M.E Biomedical Engineering from Anna University, Chennai. He is doing Ph.D degree in Sathyabama University, Chennai. His research area is Medical Instrumenttion and he has more than 20 Internaional and National Journal and Conference publications. He is have more than 7 years of teaching experience in handling Electrical, Electronics and Biomedical Engineering subjects.

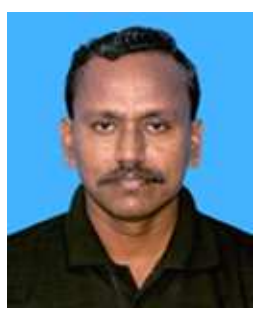

Ananda Natarajan $\mathbf{R} \mathrm{He}$ received M.E degree and Ph.D from Anna University, Chennai. He is working as professor in Electronics and Instruentation Department, Pondicherry Engineering College, Pondicherry and having more than 20 years of teaching experience. His area of specialization is Process control and having more than 40 International and National Journal and Conference publications.

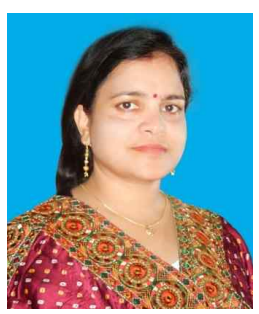

Anima Nanda She received Masters Degree and Ph.D from Berhampur University at Odisha, India. She is having more than 15 years of teaching experience and holding the post of Dean for the Faculty of Bio \& Chemical Engineering at Sathyabama University, Chennai. Her area of specialization is microbial nanotechnology and has more than 150 International and National Journal and Conference publications. To her credit she has a patent on staircase climbing wheel chair for physically challenged person. 